\title{
Modelling of shear keys in bridge structures under seismic loads
}

\author{
Kaiming $\mathrm{Bi}^{*}$, Hong Hao \\ Department of Civil Engineering, Curtin University, Kent Street, Bentley WA 6102
}

\begin{abstract}
Shear keys are used in the bridge abutments and piers to provide transverse restraints for bridge superstructures. Owing to the relatively small dimensions compared to the main bridge components (girders, piers, abutments, piles), shear keys are normally regarded as secondary component of a bridge structure, and their influences on bridge seismic responses are normally neglected. In reality, shear keys are designed to restrain the lateral displacements of bridge girders, which will affect the transverse response of the bridge deck, thus influence the overall structural responses. To study the influences of shear keys on bridge responses to seismic ground excitations, this paper performs numerical simulations of the seismic responses of a two-span simply-supported bridge model without or with shear keys in the abutments and the central pier. A detailed 3D finite element (FE) model is developed by using the explicit FE code LS-DYNA. The bridge components including bridge girders, piers, abutments, bearings, shear keys and reinforcement bars are included in the model. The nonlinear material behaviour including the strain rate effects of concrete and steel rebar are considered. The seismic responses of bridge structures without and with shear keys subjected to bi-axial spatially varying horizontal ground motions are calculated and compared. The failure mode and damage mechanism of shear keys are discussed in detail. Numerical results show that shear keys restrain transverse movements of bridge decks, which influence the torsional-lateral responses of the decks under bi-axial spatially varying ground excitations; neglecting shear keys in bridge response analysis may lead to inaccurate predictions of seismic responses of bridge structures.
\end{abstract}

Keywords: shear key; 3D model; seismic response; failure mode; damage mechanism.

*Corresponding author, Lecturer, Tel: +61 89266 5139; E-mail: kaiming.bi@curtin.edu.au; Postal address: Room 414, Building 204, Curtin University, Kent Street, Bentley WA 6102 


\section{Introduction}

Shear keys are normally used in the bridge abutments and piers to restrain the excessive transverse displacements of bridge superstructures during service load and moderate earthquakes. However, during the maximum considered earthquake, shear keys are expected to break off before damages occur in bridge abutments or piers. In other words, shear keys are designed as sacrificial elements and expected to perform as structural fuse to protect the bridge abutments or piers from damage during major earthquakes. Depending on the strength of shear key and the pounding force between shear key and corresponding bridge girder, serious, moderate or minor shear key damages were observed in many previous major earthquakes. Fig. 1(a) shows that shear keys were totally sheared off and large transverse displacements occurred at bridge girders due to loss of restraints [1]; an obvious diagonal crack developed at the stem wall of abutment is shown in Fig. 1(b) [2]; and Fig. 1(c) shows that flexural failure was initiated at the shear key-stem wall interface [3].

Seismic induced pounding responses of bridge structures have been extensively studied by many researchers. However, these studies mainly focused on the pounding between main components of bridge structures, i.e. between bridge girders or between bridge girder and adjacent abutment [e.g. 4-6]. Hao et al. [7] gave a state-of-the-art review on previous studies. It should be noted that most of previous studies modelled the bridge girder as a lumped mass or beam-column elements and the pounding by a contact element. These simplified models can be easily implemented in the FEM programs. However, because these are 1 dimensional (1D) models, they can only simulate point-to-point pounding with the pre-defined pounding locations. In a real bridge structure under seismic loading, pounding could take place along the entire surfaces of the adjacent segments. Moreover, torsional responses of adjacent girders induced by spatially varying transverse ground motions can result in eccentric poundings that occur at corners of adjacent decks. In fact most poundings observed in previous earthquakes were associated with eccentric poundings, i.e., pounding occurred at corners of adjacent bridge structures. To realistically capture the surface-to-surface and eccentric poundings, a detailed 3D finite element (FE) model is needed. More recently, Bi et al. [8] developed a detailed 3D FE model of a two-span simply-supported bridge and validated the accuracy of using LS-DYNA to simulate surface-to-surface and eccentric poundings. Bi and Hao [9] then further extended this method by involving the non-linear material properties of concrete and steel rebars in the model and examined the influences of pounding-induced local damage on bridge responses under spatially varying earthquake loadings. In the latter studies, only the poundings between adjacent bridge spans/decks are 
considered. Although shear key damages due to deck pounding have been observed in many previous earthquakes, none of these studies considered the shear keys and their influences on overall bridge responses. This paper extends the previous studies [8, 9] on detailed modelling of pounding damages between adjacent bridge spans to bi-axial spatially varying horizontal ground motions by including shear keys in the model. The poundings between shear keys and bridge decks are modelled and examined in detail. Since pounding between deck and shear key prevents excessive transverse movements of the deck and absorbs a large amount of energy, it may significantly affect the overall bridge structural responses. Therefore the influence of including shear keys in the analysis of bridge responses is also investigated and discussed in the present paper.

Limited research is available in the literature on the seismic performance of bridge shear keys. Bozorgzadeh et al. $[10,11]$ carried out experimental studies to assess the shear strength and failure mode of exterior shear keys in bridge abutments under transverse forces. Two kinds of failure mechanism, i.e. sliding shear failure and diagonal shear failure, were identified for exterior shear keys. Silva et al. performed experimental and analytical investigations to evaluate the seismic performance of sacrificial interior [13] and exterior [14] shear keys. Rational models of the force and deformation capacity of shear keys as well as their postpeak performance under cyclic loads were proposed based on the experimental data. Maleki investigated the seismic performance of ordinary [15] and skewed [16] bridges with retainers placed on each side of elastomeric bearings. Design recommendations were proposed for bridges with such retainers. Goel and Chopra [17] examined the role of shear keys at bridge abutments on the seismic behaviour of ordinary bridges crossing fault-rupture zones. Three different shear key conditions, i.e. nonlinear, linear and no shear keys, were examined. Numerical results show that seismic demands for a bridge with nonlinear shear keys can generally be bounded by the demands of a bridge with elastic shear keys and a bridge with no shear keys.

It can be seen that previous studies on the shear key mainly focused on its shear strength. The investigation of the influence of shear keys on the whole bridge responses, i.e., restraining the transverse deck movement which may influence the overall bridge responses because of the restrained torsional responses of the deck, were relatively less. Moreover, all these studies [15-17] used the simplified spring-dashpot elements to model the pounding between shear key and bridge girder/bearing, indicating only point-to-point pounding by assuming uniform contact between deck and shear key was considered. In reality, spatially 
varying earthquake ground motions always induce torsional responses on even a perfectly symmetric bridge deck, which usually cause eccentric pounding between bridge deck and shear key, as observed in many earthquakes, e.g. Fig 1(c). Thus it is important to develop a detailed 3D model that can simulate the surface-to-surface and eccentric poundings for more realistic predictions of interactions between bridge superstructures and shear keys.

In this study a two-span simply-supported bridge located at a canyon site is selected as an example to investigate the seismic induced poundings between bridge decks and shear keys and their influences on the overall bridge responses. This work is an extension of the authors' previous work [9]. The primary differences between the current study and the previous work include: (1) Detailed 3D models of shear keys are included in the numerical simulation; (2) Poundings between shear keys and bridge girders are examined in detail; (3) The influence of shear keys on overall bridge responses are discussed; (4) The failure mode and damage mechanism of shear keys due to pounding with bridge decks are examined.

Many previous studies (e.g. $[18,19])$ revealed that soil-structure interaction (SSI) can further alter the bridge responses under earthquake loadings. Not to further complicate the problem, SSI is, however, not considered in the present study since the primary aim of this study is to investigate the influence of shear keys on the seismic induced pounding responses of bridge structures. It is believed that the general observations made in this study regarding the influence of shear keys on the seismic responses of bridge structures will not be changed although SSI is not considered. In fact, this is not an uncommon practice in studying the pounding responses of engineering structures subjected to earthquake loadings, e.g. Refs [4, 5, 20-23] among many others did not consider the influence of SSI.

\section{Finite element model}

\subsection{Bridge details}

Fig. 2 shows the elevation view of a two-span simply-supported bridge located at a canyon site. The length of each box girder as shown in Fig. 3(a) is $30 \mathrm{~m}$. To allow for contraction and expansion of bridge girders from creep, shrinkage, temperature fluctuation and traffic without generating constraint forces in the structure, a $60 \mathrm{~mm}$ gap is introduced between the abutment and the bridge girder and between the adjacent girders. The cross section at the central pier is shown in Fig. 3(b). The pier foundation is a strip footing with the dimension of $6 \times 4 \times 1.8 \mathrm{~m}$. The height of the two-square-column central pier is $9 \mathrm{~m}$, and the length and width are $1.2 \mathrm{~m}$ 
respectively. Fig. 3(c) shows the cross section of the bridge column. The longitudinal steel reinforcements with a diameter of $30 \mathrm{~mm}$ are spaced at $180 \mathrm{~mm}$ on the four sizes of the pier. The stirrups of diameter $20 \mathrm{~mm}$ are spaced at $200 \mathrm{~mm}$ along the pier height. Each column has a reinforcement cover depth of $60 \mathrm{~mm}$. Two L-shaped gravity abutments are used to support the bridge at the two ends with cross section shown in Fig. 3(d). To restrain excessive lateral displacement during service and earthquake loads, one shear key is introduced at each side of the pier bent and abutments. The height of the shear keys is $0.48 \mathrm{~m}$ and the thickness is 0.24 $\mathrm{m}$. The widths are 0.96 and $1.56 \mathrm{~m}$ for shear keys at abutments and central pier respectively. The gap between shear key and corresponding bridge girder is $60 \mathrm{~mm}$ as shown in Fig. 3. The steel reinforcements, with diameters of 20 and $16 \mathrm{~mm}$, are spaced at 120 and $180 \mathrm{~mm}$ for the primary reinforcements and stirrups respectively in the bridge girder. The reinforcement bars in the shear keys at abutments and central pier are shown in Figs. 4(a) and (b). The diameters of the vertical and horizontal bars are 14 and $10 \mathrm{~mm}$ respectively.

The two bridge girders are supported by eight neoprene bearing pads. The widths of the pad in the longitudinal (x) and transverse (z) directions are 0.36 and $0.48 \mathrm{~m}$ respectively, and the thickness is $0.06 \mathrm{~m}$. The bridge is located on a canyon site, consisting of horizontally extended soil layers on a half-space (base rock) as shown in Fig. 2. Points A, B and C are the three bridge support locations on the ground surface. The corresponding points on the base rock are A', B' and C'. The soil depths for the three sites are 42, 33 and $42 \mathrm{~m}$ respectively. As mentioned above, the abutment and pier foundations are assumed rigidly fixed to the ground without considering SSI so as to focus primarily on the influence of shear keys on the seismic induced pounding responses of the bridge.

\subsection{Element and contact}

Explicit FE code LS-DYNA [24] is employed to calculate the seismic responses of the bridge. Constant stress solid elements are employed for all concrete members in this study. A previous study [9] found that a $60 \mathrm{~mm}$ mesh size can yield a good balance between the computational time and accuracy of results. The mesh size of $60 \mathrm{~mm}$ is therefore adopted in the present study to mesh the pounding prone areas. In particular, detailed modelling is applied to a length of $0.18 \mathrm{~m}$ from the backwall of the abutment, to $0.96 \mathrm{~m}$ from each end of bridge girders and to all the shear keys. Beyond these regions, the mesh size in the longitudinal direction is $0.3 \mathrm{~m}$ for the abutments and bridge girders. The bridge bent is also meshed with a fine mesh size of $60 \mathrm{~mm}$. For the pier, a mesh size of $60 \mathrm{~mm}$ is applied in the 
two horizontal directions, and in the vertical direction a $240 \mathrm{~mm}$ mesh size is employed. Reinforcement bars are also modelled in detail in the pounding prone zones, i.e., in each end of bridge girders and in the shear keys. Same mesh size of $60 \mathrm{~mm}$ is used for the Belytschko beam elements used to model the reinforcement bars. Perfect bond assumption is incorporated in the current study to model the connections between the reinforcement and concrete. Hence, the bond slip between the reinforcement and concrete is taken as a property fully dependent on failure of concrete. For places sufficiently away from the pounding prone regions, smeared models (i.e. reinforcement uniformly distributed over concrete element) are used to minimise the computational effort. Fig. 5 shows the detailed FE model of the bridge.

The contact algorithm of *CONTACT AUTOMATIC SURFACE TO SURFACE in LSDYNA is employed to model the potential poundings between abutment and the corresponding bridge girder and between two adjacent bridge girders [9]. The same contact algorithm is applied to consider the poundings between bridge girders and shear keys in the present study. It should be noted that by using this contact algorithm the dynamic and static Coulomb friction needs to be defined, which are both set to be 0.5 in this study [22, 23]. More detailed information regarding this contact algorithm can be found in [24] and [9].

\subsection{Material model}

*MAT CONCRETE DAMAGE REL3 (MAT_72REL3) in LS-DYNA is used to model the concrete of shear keys and *MAT PIECEWISE LINEAR PLASTICITY (MAT_24) is employed to model the steel reinforcements in the shear keys. For the rest parts of the bridge, the material models adopted in [9] are utilized again. To avoid repetition, they are not presented here. Table 1 tabulates the material properties. It should be noted that the bridge columns are modelled by using the smeared material model *MAT PSEUDO TENSOT (MAT_16) in the present study, the potential bridge column damages cannot be simulated. However, the inelastic behaviour of the bridge columns is still considered.

\subsection{Strain rate effect}

The concrete and steel reinforcement are strain rate dependent when subjected to high strain rate impact such as blast or earthquake pounding loads. At high strain rates, the strength of concrete and steel materials can be significantly enhanced. The strain rate effect needs to be considered for reliable prediction of structural responses. 
The effect of strain rate is typically represented by a dynamic increase factor (DIF), i.e., the ratio of dynamic to static strength versus strain rate. Many empirical equations have been proposed to estimate the strain rate effect on concrete and steel materials. The recently developed DIFs for the tensile [25] and compressive [26, 27] strengths of concrete are applied in this study for the concrete strength enhancement. Compared to the previous models, the inertial and friction confinement effects are removed in [26] and [27], and is believed to yield more accurate estimation of compressive DIF. Malvar [28] conducted a review on static and dynamic properties of reinforcing steel under high strain rate, and proposed a DIF relation for steel reinforcing bars, which is utilized in the present study. To avoid repetition, the equations of DIFs for concrete and steel are not given in the present study. More detailed information can be found in [25-28].

\section{Spatially varying ground motions}

The bridge structure as shown in Fig. 2 is located at a canyon site. Seismic wave passage effect, coherency loss effect and local site effect will result in the variations of seismic motions at supports A, B and C, which is known as the ground motion spatial variation effect. Previous studies revealed that spatially varying ground motions can significantly influence the seismic responses of bridge structures. In the present study, the recently developed approximate method [29] is adopted to simulate the multi-dimensional spatially varying ground motions at different supports of the bridge. Detailed information regarding this simulation technique can be found in [29].

In the present study, the ground motion intensities at points A', B' and C' on the base rock are assumed to be the same and are modelled by the filtered Tajimi-Kanai power spectral density functions. The duration of the base rock ground motions are assumed to be $16 \mathrm{~s}$ with a peak ground acceleration (PGA) of 0.5g. This PGA corresponds to an earthquake of magnitude 8.0 with an epicentral distance of $50 \mathrm{~km}$ [30]. The coherency loss between the ground motions on the base rock is described by the Sobczyk model [31], and weakly correlated motions are assumed. The corresponding parameters for the base rock motion and coherency loss function are the same as those in [9]. Sites A and C are soft soil sites and Site $\mathrm{B}$ is a firm soil site. Table 2 gives the corresponding parameters. Figs. 6, 7 and 8 show the acceleration, velocity and displacement time histories in the longitudinal (horizontal in-plane motions) and transverse (horizontal out-of-plane motions) directions. Fig. 9 shows the comparisons of the simulated power spectral densities with the theoretical values of the 
longitudinal motions, good agreements are observed. For conciseness, the comparisons of the transverse motions are not plotted, good agreements are also observed. The vertical motion is not included in the analysis, because: (1) The primary aim of this study is to investigate the transverse restraining effect provided by the shear keys; (2) For the far-field earthquake as considered in the present study, the vertical component is usually smaller than the horizontal components; (3) For the bridge as shown in Fig. 2, the first vertical vibration mode is the seventh mode based on an eigenvalue analysis, the contribution of vertical component on the horizontal and transverse structural responses is believed insignificant. However, it should be noted that if the bridge is subjected to a near-fault earthquake, the contribution of the vertical component might be evident and it might be necessary to consider the influence of vertical earthquake loading on the bridge seismic responses.

\section{Numerical results}

The explicit FE code LS-DYNA is used in the present study to simulate the seismic responses of the two-span simply-supported bridge as shown in Fig. 2 subjected to the biaxial spatially varying horizontal ground motions. Since the explicit solver is used, all loads including gravity load, are applied dynamically. As a result, the effect of gravity load also undergoes dynamic magnification although it is applied slowly. This undesirable dynamic effect is removed by applying a large damping to the system at the first $0.5 \mathrm{sec}$ to make the system rest. Fig. 10 shows the vertical reaction force at the left end of left girder during the initial $0.5 \mathrm{sec}$. It can be seen that slight oscillation occurs at the first $0.3 \mathrm{sec}$ due to the dynamic effect of gravity load. After $0.3 \mathrm{sec}$ the system becomes stable because of the large damping applied. The dynamic earthquake loadings are applied from 0.5 sec. It should be noted that for the seismic response time histories (Figs. 11, 17 and 18), they are plotted after earthquake loadings are applied, i.e. the initial $0.5 \mathrm{sec}$ is not plotted in these figures.

The longitudinal and transverse responses of the bridge with and without shear keys are compared and discussed in this section, and the failure mode and damage mechanism of shear keys are discussed in detail. To save modelling time, the case without shear keys is simulated with the same FE model with shear keys, but the contact algorithm between the shear keys and the corresponding bridge girders is not defined, i.e., the bridge girders can penetrate these shear keys freely. In other words, the existence of shear keys in the model does not provide any resistance to the movement of bridge girders.

\subsection{Longitudinal responses}


Fig. 11 shows the resultant pounding force time histories in the longitudinal direction at the left, middle and right gaps of the bridges with and without shear keys, which is obtained by integrating the normal stresses over the entire cross section of the contact surface. It can be seen that including shear keys in the numerical model results in different predictions of bridge longitudinal pounding responses. More pounding events but smaller ponding forces are observed when shear keys are considered. As shown in the figure, the number of collisions between adjacent components at the middle, left and right gaps are 7, 17 and 10 respectively when shear keys are not considered. When shear keys are involved, the respective numbers of longitudinal pounding events between adjacent girders or between girder and abutment are 10, 22 and 13 respectively. The maximum pounding forces reach 27.9, 26.4 and 21.2 $\mathrm{MN}$ at the three different gaps in the case of without shear keys. When shear keys are considered, the corresponding maximum pounding forces are 20.4, 16.1 and 16.5 MN respectively. This is because poundings occur mainly at corners of adjacent spans owing to torsional responses as shown in Figs. 12 and 13. When shear keys are considered, the lateral movements of bridge girders are restrained by the shear keys before they break off, which reverse the lateral movements of the deck and therefore may result in additional poundings on the opposite side of the deck. One the other hand, poundings between decks and shear keys restrict the lateral movements of the decks, which reduce the eccentric pounding forces associated with the lateral-torsional responses in the longitudinal directions as shown in Fig. 11.

Figs. 12 and 13 show the pounding damage of bridge girders without and with shear keys respectively. As shown in Fig. 12, when shear keys are not considered, the flange, web and bottom plate of the bridge girders suffer serious damages. If shear keys are considered, relatively less severe damage can be observed. This is because when shear keys are not considered, the torsional response of the deck is not restrained, which results in larger lateraltorsional displacement of the deck and larger eccentric pounding forces as shown in Fig. 11. On the other hand, when shear keys are considered, the transverse movements of bridge decks are restricted, which lead to smaller lateral-torsional displacements and smaller pounding forces. Since the contact area between adjacent structures is smaller in eccentric poundings, larger stress/strain is induced in these contact areas even the impact force is the same. Therefore more prominent local damages are generated as shown in Fig. 12. It should be noted that torsional responses of bridge decks often occur even the deck is symmetric because of the spatially varying transverse ground excitations. This is why most pounding 
damages between adjacent bridge spans observed in previous earthquakes are associated to eccentric poundings.

\subsection{Transverse responses}

Figs. 14 and 15 show the structural responses in the transverse direction at different gaps. As shown, when shear keys are not considered, large relative displacements in the transverse direction are predicted, i.e., $0.86,1.08$ and $0.84 \mathrm{~m}$ respectively at the three gaps. When shear keys are considered, the relative displacements at the corresponding gaps are 0.07, 0.08 and $0.04 \mathrm{~m}$ only. Shear keys reduce the lateral displacements of bridge girders due to the restraints provided in the transverse direction, which in turn significantly decreases the dislocation potential of the bridge girders. Fig. 16 shows the dislocation damage of the bridge without shear keys. It can be seen that, at the left and right gaps of the bridge, the bridge girders drop from the supporting bearings to the corresponding abutments. At the middle gap, the dislocation damage does not occur and it is thus not shown in the figure. The large relative displacement in the lateral direction not only results in the dislocation damage but also leads to further pounding damage at the bottom plates of bridge girders as shown in the red circles in Fig. 12. These damages are caused by the collisions between the bearing and the bridge girder after its dropping from the bearings. Pounding damages on the lateral surface of the bridge girders can also be observed when shear keys are considered as shown in the red circles in Fig. 13. These damages are, however, caused by the poundings between the bridge girders and shear keys, which will be further discussed in the last part of this section.

Fig. 17 shows the resultant transverse pounding forces between bridge girders and corresponding shear keys at different locations. Same as the resultant longitudinal pounding forces, resultant transverse pounding forces are obtained by integrating the normal stresses over the entire cross section of the contact surface. At different ends of a bridge girder, poundings between the girder and shear keys in a particular direction should occur at the same time if torsional response of the bridge deck is small. However, as shown in Fig. 17, it is obvious that at different ends of a bridge girder, pounding events do not occur at the same time. Taking the left girder as an example, the pounding events between the left end of the girder and shear key in the $+z$ direction mainly occur in the first 8 sec (Fig. 17(a)), while at the right end of the girder, they mainly occur in the last 8 sec (Fig. 17(b)). Similar results can be obtained by comparing Figs. 17(c) and (d). These results clearly show the torsional responses of bridge girders induced by spatially varying transverse ground motions. 
Piers are the most critical component of bridge designs. The influence of lateral pounding on the internal forces developed in the central pier is examined. Since poundings between shear keys and bridge girders occur in the transverse direction, only the shear force in the transverse direction $(\mathrm{Fz})$ and the corresponding bending moment $(\mathrm{Mx})$ are examined. For the internal forces in the longitudinal direction, the influence of shear keys is relatively less, and they are not presented in the paper. Fig. 18 shows the time histories of $\mathrm{Fz}$ and $\mathrm{Mx}$ at the bottom section of central pier as shown in Fig. 2. As shown, the internal forces are the same in the first $2.02 \mathrm{~s}$ for the two cases. This is because the first transverse pounding occurs between the right end of right girder and the shear key in the $-\mathrm{z}$ direction at $2.02 \mathrm{~s}$ as shown in Fig. 17(d). Before this instant the structural responses will not be influenced by the shear keys. Poundings between girders and shear keys alter the subsequent responses of the bridge structure and the internal forces developed in the central pier. It can be seen that pounding results in abrupt increases in the internal forces. For example, Fz and Mx increase suddenly at 6.23s (marked with star) as shown in Figs. 18(a) and (b), because a collision occurs between the left end of right girder and the shear key in the $+\mathrm{z}$ direction at central pier at this moment as shown in Fig. 17(c). The sudden pounding force on the shear key will inevitably increase the internal forces in the pier. Since larger internal forces can develop in the pier due to poundings between bridge girders and shear keys, it may increase the damage potential of bridge piers. However, due to the extensive computational effort, the pier damage is not simulated in the present work. Further research is needed to investigate the influence of poundings between bridge girders and shear keys on the pier damage.

\subsection{Shear key damage}

It also can be seen from Fig. 17 that for most of the pounding forces, the durations are between $0.1 \sim 0.3 \mathrm{sec}$ and they can be approximately regarded as triangular pulses (see the enlarged figure in Figs. 17 (a) and (d)). It is well known that for a system subjected to a pulse force, the structural response can be amplified or de-amplified and the maximum response is related to the ratio of $t_{d} / T_{n}$ [33], where $t_{d}$ is the pulse duration and $T_{n}$ is the natural vibration period of the system. For the shear keys as shown in Fig. 2, it is found that the first vibration periods are $T_{n}=2.76 \times 10^{-3}$ and $1.75 \times 10^{-3}$ sec respectively for the shear keys at left/right and middle gaps based on an eigenvalue analysis. $t_{d} / T_{n}$ thus varies from 36.2 to 171.4. For such a large $t_{d} / T_{n}$, the response can be considered as quasi-static with minimum dynamic amplification [33], and the maximum pounding forces acted on the shear keys will be the same as those shown in Fig. 17. The relationship between the maximum pounding force and 
the nominal capacity of shear key, which will be discussed in the following paragraphs, can then be used to explain the damage mechanism of shear keys.

Pounding between bridge girders and shear keys can result in different damage patterns of shear keys at different locations as shown in Fig. 19. Figs. 19(a) and (f) show that transverse poundings lead to diagonal shear failure of shear keys in the $+\mathrm{z}$ direction at left gap and $-\mathrm{z}$ direction at right gap respectively. Similar shear damages have been observed in many previous major earthquakes, for example the damage case shown in Fig. 1(b). For the shear key in the $-\mathrm{z}$ direction at left gap (Fig. 19(b)), in the $-\mathrm{z}$ direction at the middle gap (Fig. 19(d)) and in the $+z$ direction at the right gap (Fig. 19(e)), no damage or only minor damage occurs owing to the relatively less number of poundings and smaller pounding forces as shown in Figs. 17(a), (c) and (d). For the shear key in the $+z$ direction at the middle gap (Fig. 19(c)), flexural failure occurs and spalling damage of the cover concrete is observed.

The damage pattern as shown in Fig. 19 can be further explained by examining the relationship between the pounding force and the strength of shear keys as mentioned above. The nominal capacity of shear key in the tension failure mechanism can be computed by [10, $11]$

$$
\mathrm{V}_{\mathrm{n}}=\mathrm{V}_{\mathrm{c}}+\mathrm{V}_{\mathrm{s}}
$$

where $V_{c}$ and $V_{s}$ are the contributions from the concrete and steel reinforcements respectively. $\mathrm{V}_{\mathrm{c}}$ is given by

$$
\mathrm{V}_{\mathrm{c}}=0.2 \sqrt{\mathrm{f}_{\mathrm{c}}^{\prime}} \mathrm{bh}
$$

where $\mathrm{f}_{\mathrm{c}}^{\prime}$ is the compressive strength of the concrete (in MPa), and $\mathrm{h}$ and $\mathrm{b}$ are the height and width of the stem wall respectively.

The contribution of steel, $\mathrm{V}_{\mathrm{s}}$, is given by

$$
V_{s}=\left[A_{s 1} f_{y} h+A_{s 2} f_{y} d+n_{h} A_{s h} f_{y} \frac{h^{2}}{2 s}+n_{v} A_{s v} f_{y} \frac{d^{2}}{2 s}\right]\left(\frac{1}{h+a}\right)
$$

where $A_{s 1}$ is the total area of the horizontal tie bars; $A_{s 2}$ is the total area of the inclined bars in the first row crossing the shear key interface; $A_{s h}$ and $A_{s v}$ are the area of single horizontal and vertical bars respectively; $\mathrm{n}_{\mathrm{h}}$ and $\mathrm{n}_{\mathrm{v}}$ are the number of side faces with horizontal and 
vertical bars; $d$ is the thickness of shear key; $\mathrm{f}_{\mathrm{y}}$ is the yield strength of steel reinforcement bars; and $a=0.167 d$.

For the abutment shown in Fig. 2, there is no horizontal tie bars and inclined bars, so $\mathrm{A}_{\mathrm{s} 1}=\mathrm{A}_{\mathrm{s} 2}=0$, other parameters and calculated concrete and steel contributions are listed in Tables 3 and 4 respectively. It can be calculated that the contributions of concrete to the shear key resistance capacity at the left/right and middle gaps are 0.757 and $1.640 \mathrm{MN}$ respectively, and the corresponding contributions from the steel are 0.689 and 1.193 MN. The nominal capacities of shear keys at left/right and middle gaps in the diagonal tension mechanism are thus 1.446 and 2.833 MN respectively.

As mentioned above, the dynamic amplification effect on the shear keys due to pounding can be neglected. The maximum pounding forces act on the shear key in the $+\mathrm{z}$ direction at left gap and in the $-\mathrm{z}$ direction at right gap are 1.65 and $1.70 \mathrm{MN}$ respectively as shown in Figs. 17(a) and (d), which are larger than the nominal shear capacity of $1.466 \mathrm{MN}$. Therefore diagonal shear failures are obtained as shown in Figs. 19(a) and (f). For the shear keys on bridge pier, the maximum pounding forces are 1.86 and 1.46 $\mathrm{MN}$ respectively as shown in Figs 17(b) and (c), which are smaller than the nominal shear capacity of $2.833 \mathrm{MN}$. The diagonal shear failure thus does not occur and only moderate spalling damage or minor damage occurs as shown in Figs. 19(c) and (d). It should be noted that only the maximum pounding force is compared with the capacity of shear key when explaining the damage mechanism in the present study. In fact, relatively smaller poundings can occur before the maximum pounding appears as shown in Fig. 17, these poundings may have already caused some damages to shear keys, implying when the maximum pounding occurs, the shear key capacity might be smaller than the nominal capacity calculated based on the intact model. Since no models are available to calculate the strength of damaged shear key, the intact model is used in the present study. It might lead to slightly non-conservative estimation of shear key damage.

To more clearly examine the pounding phenomena between bridge girders and shear keys, the snapshots of pounding damage between left end of left girder and shear key in the $+\mathrm{z}$ direction at left gap are taking as an example and the results are shown in Fig. 20. As shown in Fig. 20(a), an original gap of $60 \mathrm{~mm}$ is set between the bridge girder; the first pounding occurs at $3.57 \mathrm{sec}$, which results in relatively high strain around the contacting zone at the bottom plate and the corner of shear key as shown in Fig. 20(b); minor damage begins to 
appear at shear key when the second collision occurs at $4.21 \mathrm{sec}$ (Fig. 20(c)) when the strain reaches the erosion strain of 0.15 ; further damage develops at shear key and bottom plate of bridge girder at $6.36 \mathrm{sec}$ due to the third collision (Fig. 20(d)); the horizontal reinforcement bars begin to break off at $8.0 \mathrm{sec}$ (Fig. 20(e)) and more layers of concrete spall off in the shear key and finally result in the tension failure as shown in Fig. 20(f). Similar damage process occurs to the shear key in the $-\mathrm{z}$ direction at right gap. To avoid repetition, this damage process is not discussed again. For shear keys at middle gap, since only moderate or minor spalling damage is observed as shown in Figs. 19(c) and (d), the damage process is not presented.

\section{Conclusions}

Shear keys are used in the bridge abutments and piers to restrain the excessive transverse displacements of bridge superstructures during service load and moderate earthquakes. During maximum considered earthquake, shear keys can break off due to the large pounding force between shear key and bridge girder. Previous studies on pounding responses of bridge structures mainly focused on the main bridge components, the influence of shear keys is rarely investigated. This paper carries out numerical simulation on the influence of shear keys on the seismic responses of bridge structures. A two-span simply-supported bridge located at a canyon site is taken as an example and the seismic responses are calculated by using the explicit FE code LS-DYNA based on a detailed 3D FE model. The bi-axial spatially varying horizontal ground motions are stochastically simulated based on the combined onedimensional wave propagation theory and conventional spectral representation method. The seismic responses of bridges with and without shear keys are investigated and compared, and the failure mode and damage mechanism of shear keys are examined in detail. The influence of pounding between bridge girders and shear keys on the pier internal forces is also discussed. The numerical results demonstrate that neglecting shear keys in bridge response analysis may lead to inaccurate predictions of bridge responses to seismic ground excitations. It is also found that:

1. Shear keys alter the seismic responses of bridge structures. Shear keys restrain transverse movements of bridge decks and hence reduces its lateral-torsional responses, which result in smaller pounding forces and less severe pounding damages to bridge decks;

2. Shear keys can significantly decrease the dislocation potential of bridge girders; 
3. Poundings between bridge girders and shear keys can increase the internal forces in the bridge piers in the transverse direction and therefore increase the damage potential of bridge piers.

The current study demonstrated the important influences of poundings between bridge deck and shear keys, which are normally neglected, on bridge structural responses when they are subjected to earthquake ground motions. It should be noted that many parameters, for example SSI, vertical earthquake loading, the dimensions of shear keys, ground motion spatial variations, gap size at expansion joints and gap size between shear key and bridge girder, may significantly influence the structural responses. Further parametric investigations are needed to study the influences of these parameters on pounding responses of shear keys.

\section{Acknowledgement}

The authors acknowledge the partial financial support from ARC Linkage Project LP110200906 for carrying out this research.

\section{References}

[1] Lee GC. The 512 Wenchuan earthquake of China-a preliminary report. MCEER, University at Buffalo. http://mceer.buffalo.edu/research/Reconnaissance/China5-1208/ChinaEQ6-15-08.pdf.

[2] Li J, Peng T, Xu, Y. Damage investigation of girder bridges under Wenchuan earthquake and corresponding seismic design recommendations. Earthq Eng Eng Vib 2008; 7(4), 33744.

[3] Schanack F, Valdebenito G, Alvial J. Seismic damage to bridges during the 27 February 2010 magnitude 8.8 Chile Earthquake. Earthq Spectra 2012; 28(1): 301-15.

[4] Jankowski R, Wilde K, Fujino Y. Pounding of superstructure segments in isolated elevated bridge during earthquakes. Earthq Eng Struct Dyn 1998; 27(5): 487-502.

[5] DesRoches R, Muthukumar S. Effect of pounding and restrainers on seismic response of multi-frame bridges. J Struct Eng-ASCE 2002; 128(7): 860-9.

[6] Guo A, Li Z, Li H, Ou J. Experimental and analytical study on pounding reduction of base-isolated high way bridges using MR damper. Earthq Eng Struct Dyn 2009; 38(11): 1307-33.

[7] Hao H, Bi K, Chouw N, Ren WX. State-of-the-art review on seismic induced pounding response of bridge structures. J Earthq and Tsunami 2013; 7(3): 1350019. 
[8] Bi K, Hao H, Chouw N. 3D FEM analysis of pounding response of bridge structures at a canyon site to spatially varying ground motions. Adv Struct Eng 2013; 16(4): 631-52.

[9] Bi K, Hao H. Numerical simulation of pounding damage to bridge structures under spatially varying ground motions. Eng Struct 2013; 46: 62-76.

[10] Bozorgzadeh A, Megally S, Restrepo J. Seismic response of sacrificial exterior shear keys in bridge abutments: recommended design and construction details. Report to CALTRANS, Contract No. 59A0337, Department of Structural Engineering, UC San Diego, San Diego.

[11] Bozorgzadeh A, Megally S, Restrepo J, Ashford SA. Capacity evaluation of exterior sacrificial shear keys of bridge abutments. J Bridge Eng-ASCE 2006; 11(5): 555-65.

[13] Silva PF, Megally S, Seible F. Seismic performance of sacrificial interior shear keys. ACI Struct J 2003; 100(2): 177-87.

[14] Silva PF, Megally S, Seible F. Seismic performance of sacrificial exterior shear keys in bridge abutments. Earthq Spectra 2011; 25(3): 643-64.

[15] Maleki S. Effect of side retainers on seismic response of bridges with elastomeric bearings. J Bridge Eng-ASCE 2004; 9(1): 95-100.

[16] Maleki S. Seismic modelling of skewed bridges with elastomeric bearings and side retainers. J Bridge Eng-ASCE 2005; 10(4), 442-9.

[17] Goel RK, Chopra AK. Role of shear keys in seismic behaviour of bridges crossing faultrupture zones. J Bridge Eng-ASCE 2008; 13(4): 398-408.

[18] Chouw N, Hao H. Study of SSI and non-uniform ground motions effects on pounding between bridge girders. Soil Dyn Earthq Eng 2005; 23: 717-28.

[19] Chouw N, Hao H. Significance of SSI and non-uniform near-fault ground motions in bridge response I: effect on response with conventional expansion joint. Eng Struct 2008; 30(1): 141-53.

[20] Zhu P, Abe M, Fujino Y. Modelling three-dimensional non-linear seismic performance of elevated bridges with emphasis on pounding of girders. Earthq Eng Struct Dyn 2002; 31:1891-913.

[21] Abdel Raheem SE. Pounding mitigation and unseating prevention at expansion joints of isolated multi-span bridges, Eng Struct 2009; 31(10): 2345-56.

[22] Jankowski R. Non-linear FEM analysis of earthquake-induced pounding between the main building and the stairway tower of the Olive View Hospital. Eng Struct 2009; 31(8): 1851-64. 
[23] Jankowski R. Non-linear FEM analysis of pounding-involved response of buildings under non-uniform earthquake excitation. Eng Struct 2012; 37: 99-105.

[24] LS-DYNA. LD-DYNA user manual. Livermore Software Technology Corporation; 2007.

[25] Hao Y, Hao H, Zhang XH. Numerical analysis of concrete material properties at high strain rate under direct tension. Inte J of Impact Eng 2012; 39: 51-62.

[26] Hao Y, Hao H. Numerical evaluation of the influence of aggregates on concrete compressive strength at high strain rate. Int J of Prot Struct 2011; 2(2): 177-206.

[27] Hao Y, Hao H, Li ZX. Influence of end friction confinement on impact tests of concrete material at high strain rate. Int J of Prot Struct 2013; 60: 82-106.

[28] Malvar LJ. Review of static and dynamic properties of steel reinforcing bars. ACI Mater J 1998; 95(6): 609-16.

[29] Bi K, Hao H. Modelling and simulation of spatially varying earthquake ground motions at sites with varying conditions. Probabilistic Eng Mech 2012; 29: 92-104.

[30] Wang S, Hao H. Effects of random variations of soil properties on site amplification of seismic ground motions. Soil Dyn Earthq Eng 2002; 22: 551-64.

[31] Sobczky K. Stochastic wave propagation. Netherlands: Kluwer Academic Publishers; 1991.

[32] Chopra, A.K. Dynamics of structures: theory and applications to earthquake engineering. New Jersey: Prentice-Hall; 1995. 
Table 1. Material properties

\begin{tabular}{|c|c|c|c|c|}
\hline Material & Location & LS-DYNA model & Parameter & Value \\
\hline \multirow{12}{*}{ Concrete } & \multirow{2}{*}{$\begin{array}{l}\text { Fine mesh area on } \\
\text { bridge girders }\end{array}$} & \multirow{2}{*}{ MAT_72REL3 } & Mass density & $2400 \mathrm{~kg} / \mathrm{m}^{3}$ \\
\hline & & & Compressive strength & $50 \mathrm{MPa}$ \\
\hline & \multirow{4}{*}{$\begin{array}{l}\text { Smeared concrete on } \\
\text { bridge girders }\end{array}$} & \multirow{4}{*}{ MAT_16 } & Mass density & $2500 \mathrm{~kg} / \mathrm{m}^{3}$ \\
\hline & & & Shear modulus & 14.37 GPa \\
\hline & & & Poisson's ratio & 0.2 \\
\hline & & & Percent reinforcement & $2.0 \%$ \\
\hline & \multirow{2}{*}{ Shear keys } & \multirow{2}{*}{ MAT_72REL3 } & Mass density & $2400 \mathrm{~kg} / \mathrm{m}^{3}$ \\
\hline & & & Compressive strength & $30 \mathrm{MPa}$ \\
\hline & \multirow{4}{*}{$\begin{array}{l}\text { Smeared concrete on } \\
\text { abutment/pier }\end{array}$} & \multirow{4}{*}{ MAT_16 } & Mass density & $2500 \mathrm{~kg} / \mathrm{m}^{3}$ \\
\hline & & & Shear modulus & $12.5 \mathrm{GPa}$ \\
\hline & & & Poisson's ratio & 0.2 \\
\hline & & & Percent reinforcement & $1.1 \%$ \\
\hline \multirow{6}{*}{ Steel } & \multirow{6}{*}{$\begin{array}{l}\text { Bridge girders/shear } \\
\text { keys }\end{array}$} & \multirow{6}{*}{ MAT_24 } & Density & $7850 \mathrm{~kg} / \mathrm{m}^{3}$ \\
\hline & & & Young's modulus & $200 \mathrm{GPa}$ \\
\hline & & & Poisson's ratio & 0.3 \\
\hline & & & Yield stress & $480 \mathrm{MPa}$ \\
\hline & & & Tangent modulus & $1600 \mathrm{MPa}$ \\
\hline & & & Failure strain & 0.13 \\
\hline \multirow{4}{*}{ Neoprene pads } & \multirow{4}{*}{ Bearing } & \multirow{4}{*}{ MAT_6 } & Mass density & $2300 \mathrm{~kg} / \mathrm{m}^{3}$ \\
\hline & & & Bulk modulus & $182 \mathrm{MPa}$ \\
\hline & & & Short-time shear modulus & $18.35 \mathrm{MPa}$ \\
\hline & & & Infinite shear modulus & $17.32 \mathrm{MPa}$ \\
\hline
\end{tabular}

Table 2. Parameters for local soil conditions

\begin{tabular}{|c|c|c|c|c|}
\hline Type & $\begin{array}{c}\text { Density } \\
\left(\mathrm{kg} / \mathrm{m}^{3}\right)\end{array}$ & $\begin{array}{c}\text { Shear modulus } \\
(\mathrm{MPa})\end{array}$ & Damping ratio & Poisson's ratio \\
\hline Base rock & 3000 & 1800 & 0.05 & 0.33 \\
\hline Firm soil & 2000 & 320 & 0.05 & 0.4 \\
\hline Soft soil & 1600 & 60 & 0.05 & 0.4 \\
\hline
\end{tabular}


Table 3. Parameters for calculating $V_{c}$

\begin{tabular}{|c|c|c|c|c|}
\hline Location & $\mathrm{b}(\mathrm{m})$ & $\mathrm{h}(\mathrm{m})$ & $f_{c}^{\prime}(\mathrm{MPa})$ & $V_{c}(\mathrm{MN})$ \\
\hline Left/right gaps & 0.96 & 0.72 & 30 & 0.757 \\
\hline Middle gap & 1.56 & 0.96 & 30 & 1.640 \\
\hline
\end{tabular}

Table 4. Parameters for calculating $V_{S}$

\begin{tabular}{|c|c|c|c|c|c|c|c|c|}
\hline Location & $n_{h}$ & $A_{s h}\left(\mathrm{~m}^{2}\right)$ & $\begin{array}{c}f_{y} \\
(\mathrm{MPa})\end{array}$ & $s(\mathrm{~m})$ & $n_{v}$ & $\begin{array}{c}A_{s v} \\
\left(\mathrm{~m}^{2}\right)\end{array}$ & $\mathrm{d}(\mathrm{m})$ & $\begin{array}{c}V_{s} \\
(\mathrm{MN})\end{array}$ \\
\hline Left/right gaps & 6 & $7.854 \mathrm{e}-5$ & 480 & 0.12 & 2 & $1.54 \mathrm{e}-4$ & 0.24 & 0.689 \\
\hline Middle gap & 8 & $7.854 \mathrm{e}-5$ & 480 & 0.12 & 2 & $1.54 \mathrm{e}-4$ & 0.24 & 1.193 \\
\hline
\end{tabular}




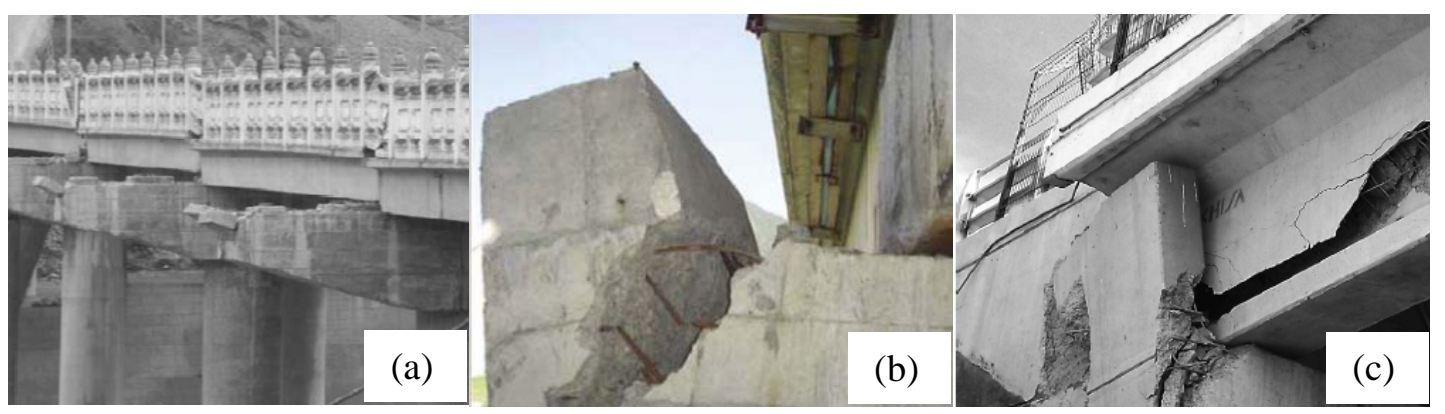

Fig. 1. Typical shear key damages: (a) totally shear off [1]; (b) diagonal shear failure [2]; and (c) flexural failure [3]

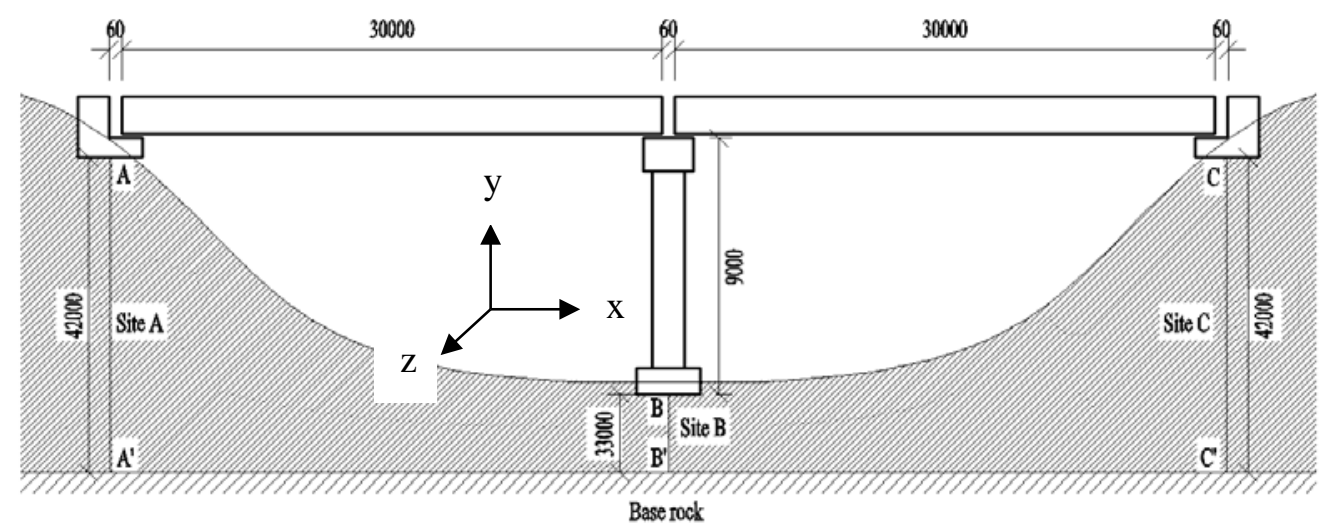

Fig. 2. Elevation view of a two-span simply-supported bridge at a canyon site (not to scale, unit: mm) 




(a)



(c)



(b)

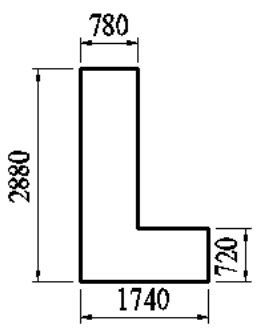

(d)

Fig. 3. Cross sections (a) box girder, (b) central pier, (c) bridge column and (d) abutment (not to scale, unit: $\mathrm{mm}$ )
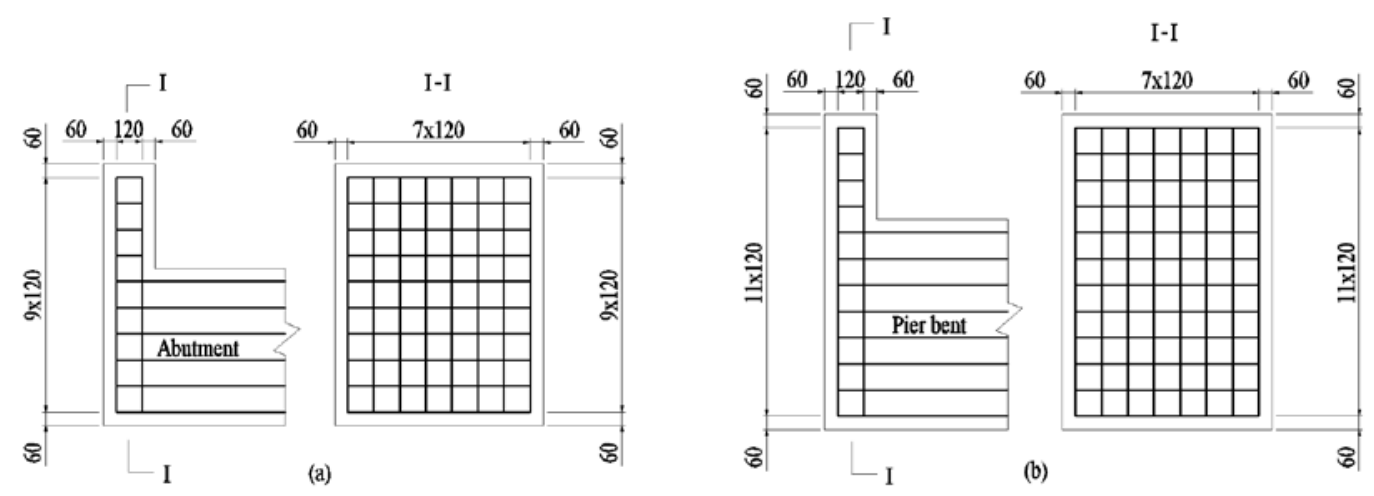

Fig. 4. Reinforcement bars in the shear keys (a) on abutments and (b) on pier (not to scale, unit: mm) 


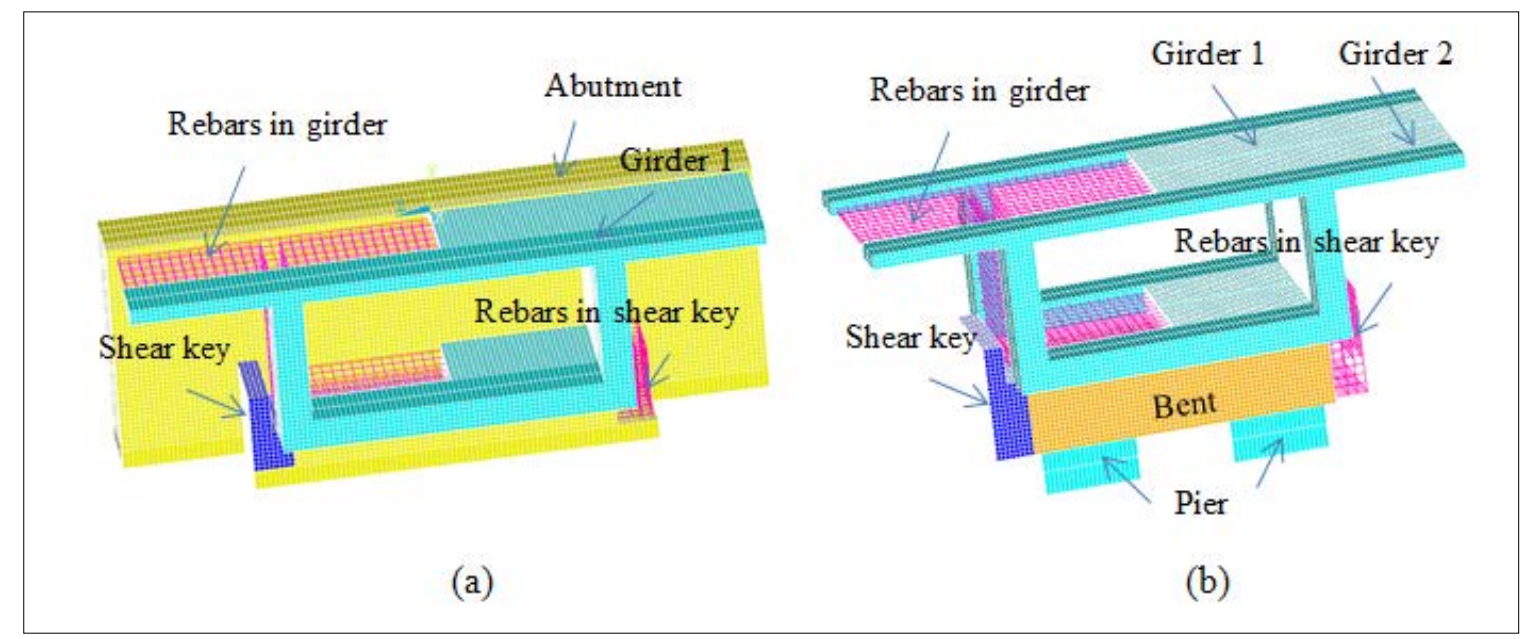

Fig. 5. Detailed finite element model of bridge girders at (a) left abutment and (b) central pier

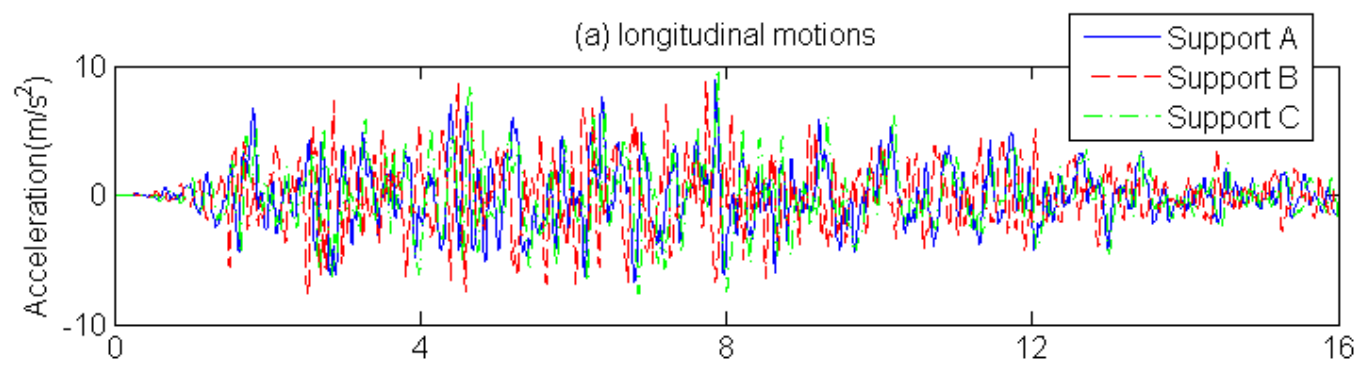

(b) transverse motions

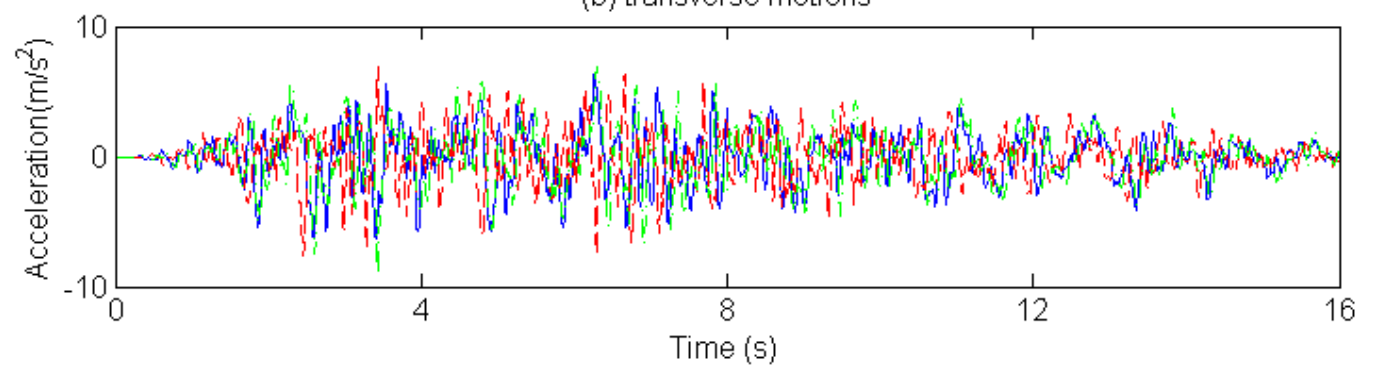

Fig. 6. Simulated acceleration time histories in (a) longitudinal direction and (b) transverse direction 




(b) transverse motions



Fig. 7. Simulated velocity time histories in (a) longitudinal direction and (b) transverse direction

(a) longitudinal motions

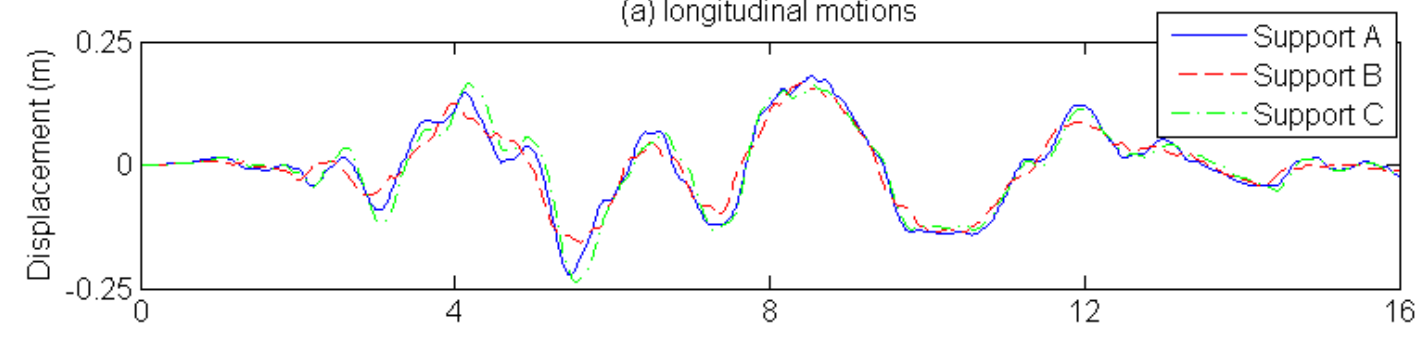

(b) transverse motions

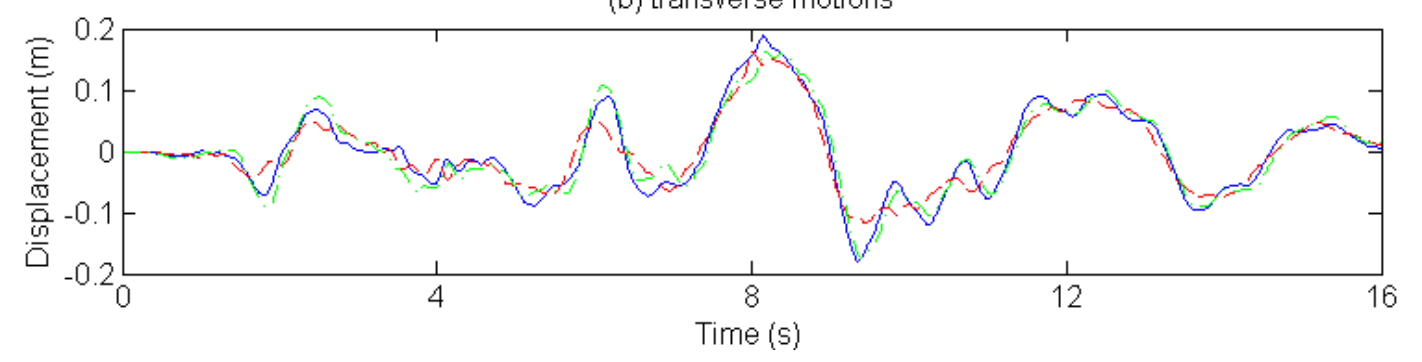

Fig. 8. Simulated displacement time histories in (a) longitudinal direction and (b) transverse direction 

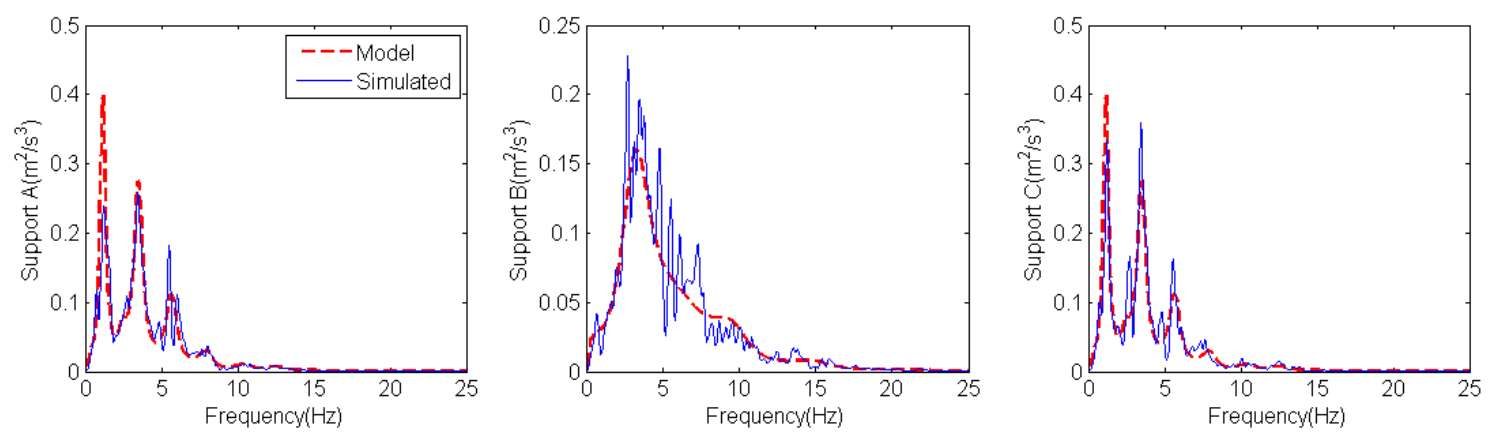

Fig. 9. Comparison of PSDs between generated longitudinal motions on ground surface with the respective target PSDs

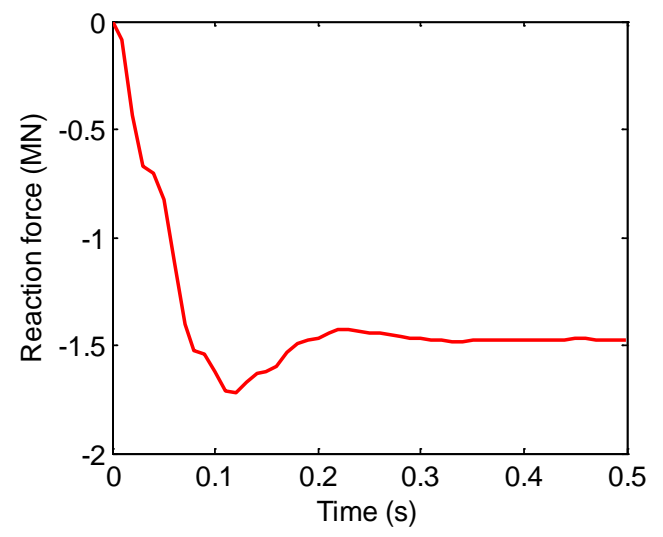

Fig. 10. Vertical reaction force at left end of left girder 
(a) Left gap

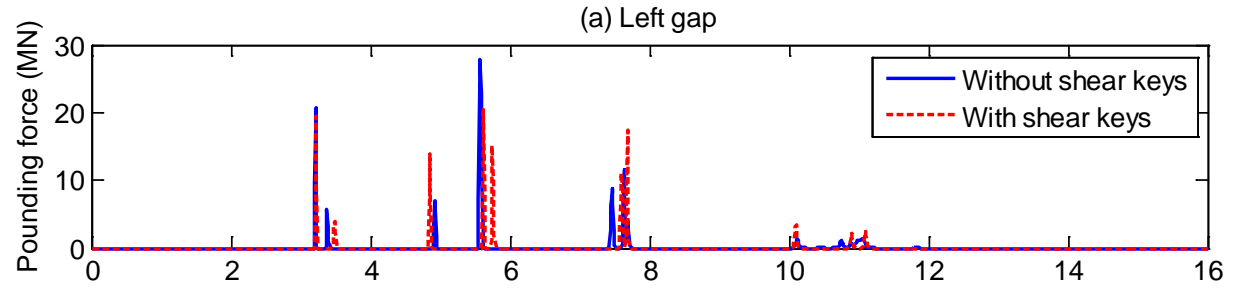

(b) Middle gap



(c) Right gap

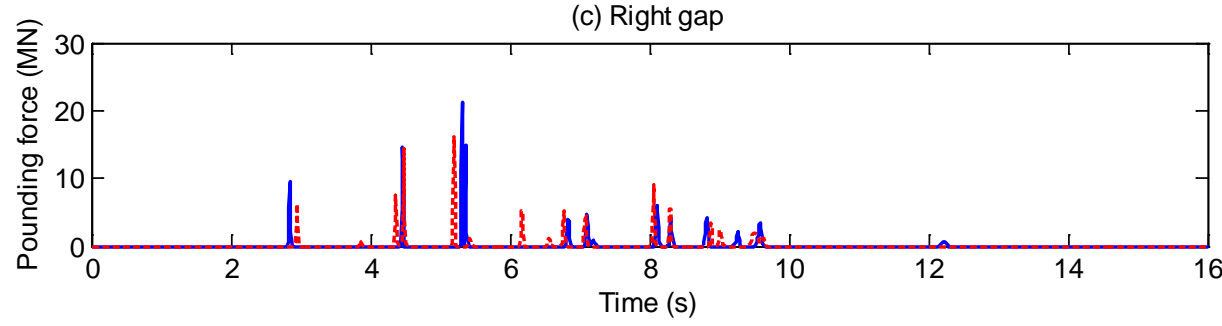

Fig. 11. Longitudinal pounding forces at different gaps of the bridges with and without shear keys (a) left gap, (b) middle gap and (c) right gap

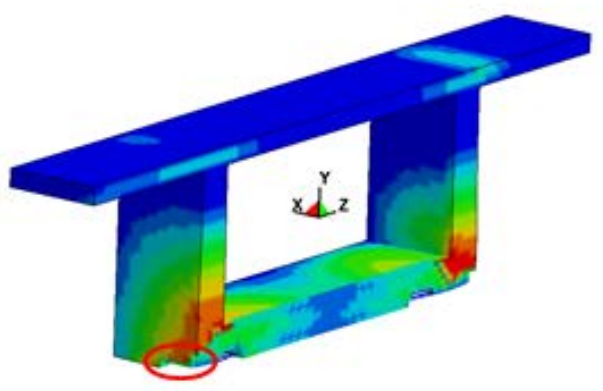

(a)

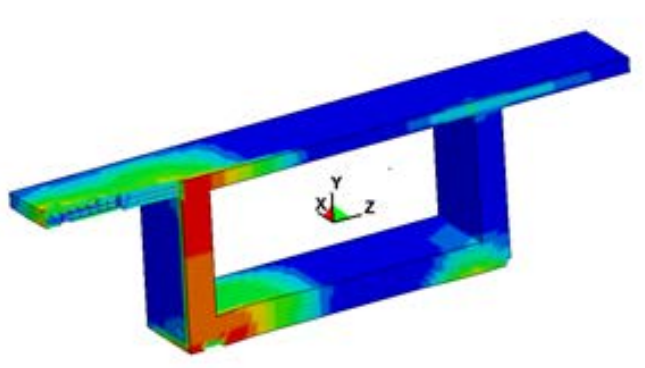

(c)

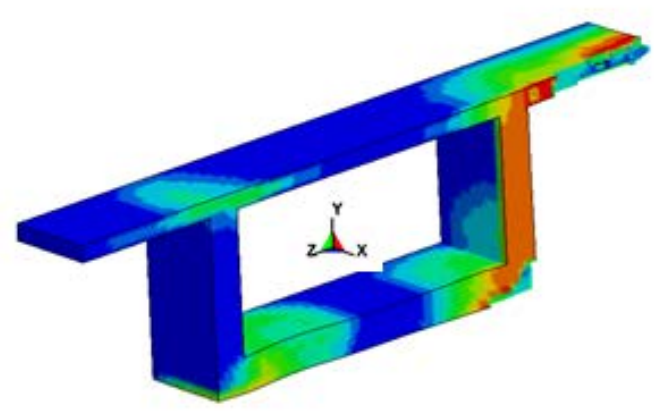

(b)



(d)

Fig. 12. Pounding damage to bridge without shear keys (a) left end of left girder, (b) right end of left girder, (c) left end of right girder and (d) right end of right girder 


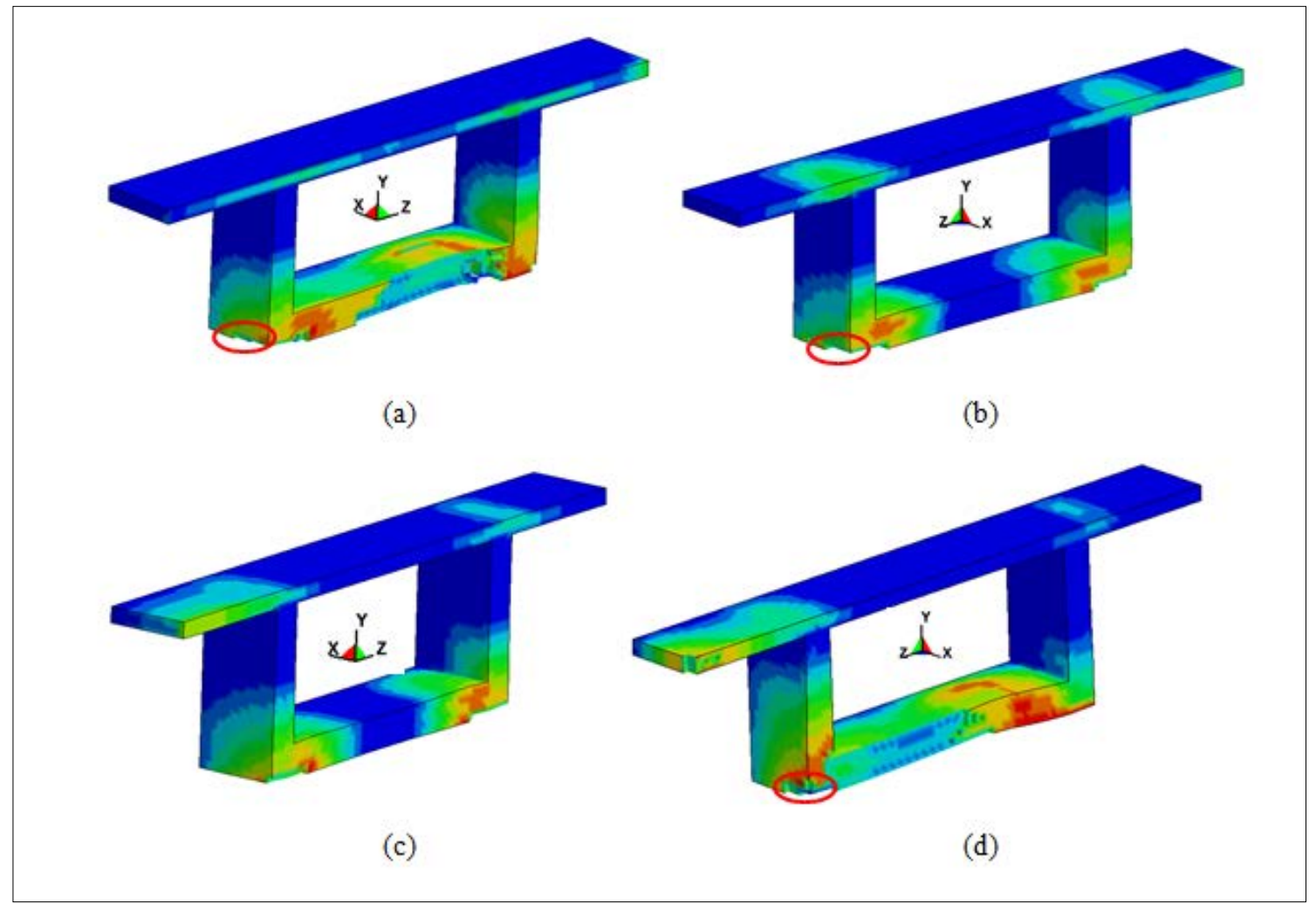

Fig. 13. Pounding damage to bridge with shear keys (a) left end of left girder, (b) right end of left girder, (c) left end of right girder and (d) right end of right girder



Fig. 14. Structural response in the transverse direction of bridge without shear keys (a) left gap, (b) middle gap and (c) right gap 


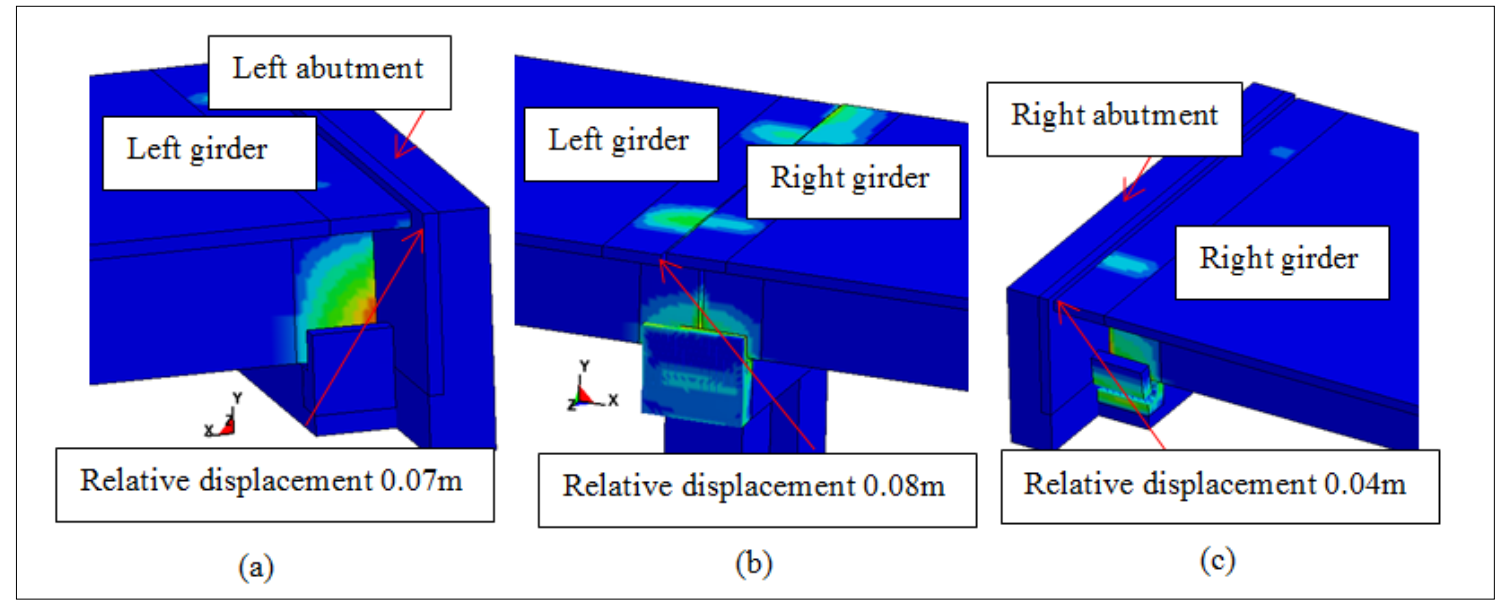

Fig. 15. Structural response in the transverse direction of bridge with shear keys (a) left gap, (b) middle gap and (c) right gap



Fig. 16. Dislocation damage to bridge without shear keys (a) left gap and (b) right gap 
(a) Left end of left girder



(c) Left end of right girder



(b) Right end of left girder

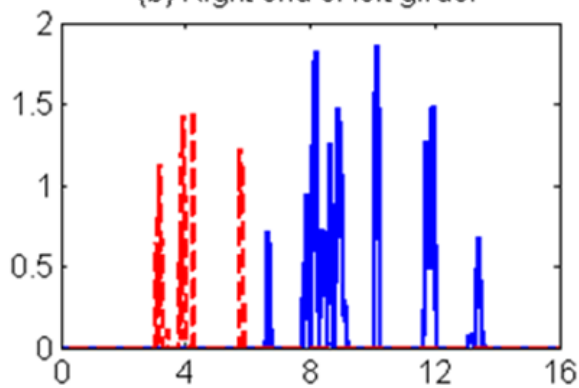

(d) Right end of right girder

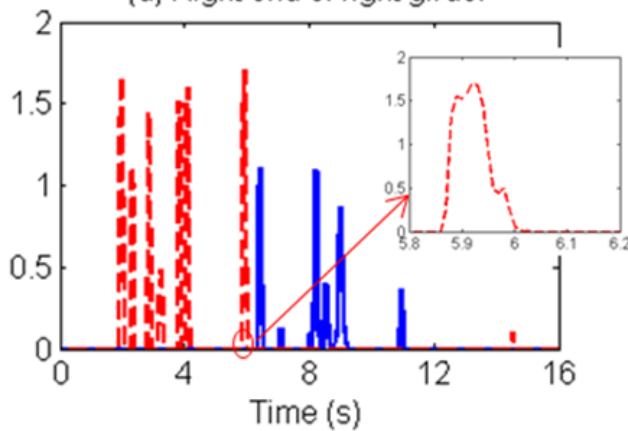

Fig. 17. Transverse pounding forces between bridge girders and corresponding shear keys at different locations (a) left end of left girder, (b) right end of left girder, (c) left end of right girder and (d) right end of right girder
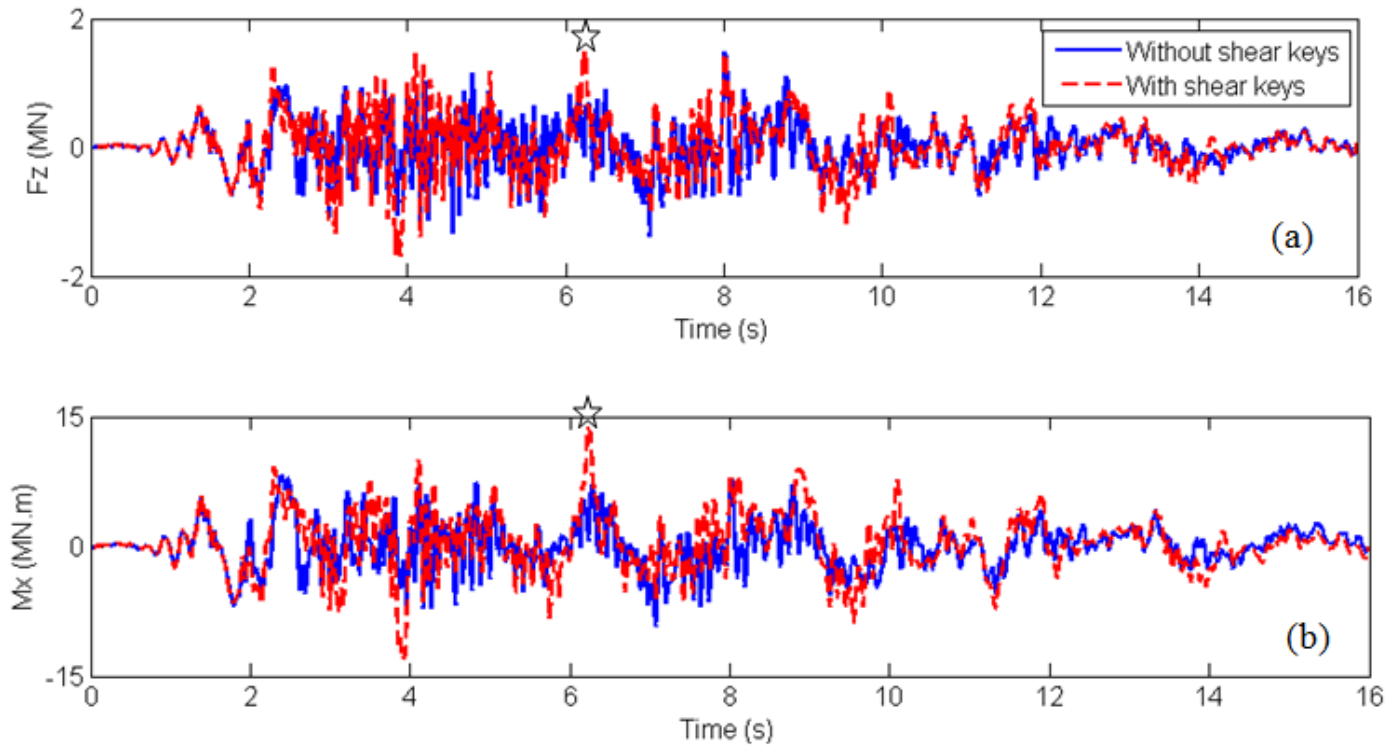

Fig. 18. Internal force time histories in the central pier (a) shear force Fz and (b) bending moment Mx 


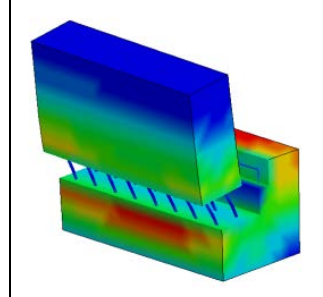

(a)

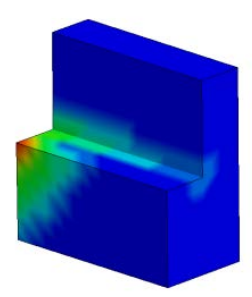

(b)

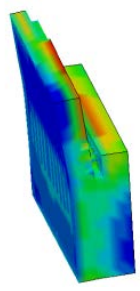

(c)

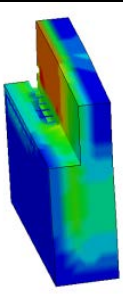

(d)

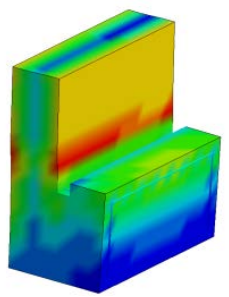

(e)

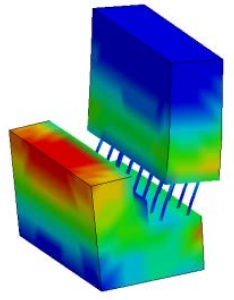

(f)

Fig. 19. Pounding damage to shear keys at different locations (a) $+z$ direction at left gap, (b) $-\mathrm{z}$ direction at left gap, (c) $+\mathrm{z}$ direction at middle gap, (d) $-\mathrm{z}$ direction at middle gap, (e) $+\mathrm{z}$ direction at right gap and (f) $-\mathrm{z}$ direction at right gap

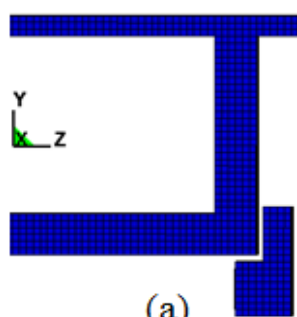

(a)

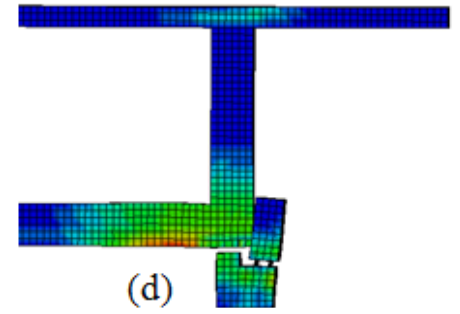

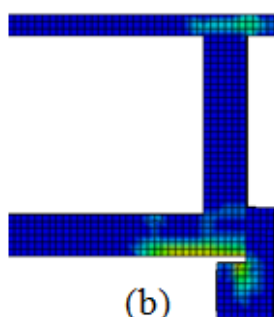

(b)





(c)

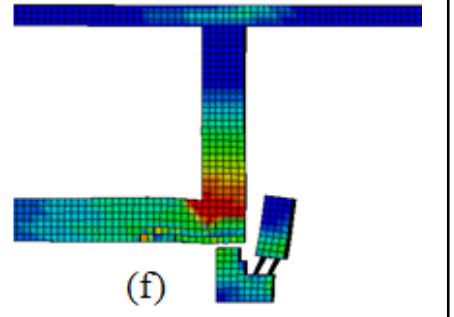

Fig. 20. Snapshots of pounding damage between left end of left girder and shear key in the $+z$ direction at left gap (a) $t=0 \mathrm{~s}$, (b) $t=3.57 \mathrm{~s}$, (c) $\mathrm{t}=4.21 \mathrm{~s}$, (d) $\mathrm{t}=6.36 \mathrm{~s}$, (e) $\mathrm{t}=8.00 \mathrm{~s}$ and (f) $\mathrm{t}=16 \mathrm{~s}$ 